\title{
O terceiro-mundismo no campo cultural argentino: uma sensibilidade hegemônica (1961-1987) ${ }^{1}$
}

\author{
Germán Alburquerque[1]
}

\begin{abstract}
Resumo
Este artigo estuda a trajetória do Terceiro Mundo e do terceiro-mundismo na Argentina e tenta explicar como isso se constitui em uma sensibilidade hegemônica ao interior do campo intelectual de tal país, entre as décadas de 1960 e 1970. Com este objetivo, foram examinadas as disciplinas, as tendências políticas e os movimentos culturais que colocaram o Terceiro Mundo no centro de suas preocupações. Palavras-chave: terceiro mundo; terceiro-mundismo; campo intelectual argentino.
\end{abstract}

\section{El tercermundismo en el campo cultural argentino: una sensibilidad hegemóni- ca (1961-1987)}

\section{Resumen}

El artículo estudia el recorrido del Tercer Mundo y del tercermundismo en Argentina e intenta explicar cómo éste logró constituirse en una sensibilidad hegemónica al interior del campo intelectual de ese país entre las décadas del sesenta y setenta. Con ese fin, se revisaron las disciplinas, las tendencias políticas y los movimientos culturales que pusieron el Tercer Mundo entre sus preocupaciones centrales. Palabras clave: tercer mundo; tercermundismo; campo intelectual argentino.

The third-worldism in the Argentinian intellectual field: a hegemonic sensibility (1961-1987)

Abstract

This article studies the trajectory of the Third World and third-worldism in Argentina and tries to explain how its sensibility occupied a decisive place in the Argentinian intellectual field in the 1960s and 1970s. With this purpose, the disciplines, political tendencies, and cultural movements that put the Third World between their main worries were reviewed.

Keywords: third world; third-worldism; Argentinian intellectual field.

\section{Le tiers-mondisme dans le domaine culturel argentin: sensibilité} hégémonique (1961-1987)

Résumé

Cet article étudie la trajectoire du tiers-monde et du tiers-mondisme en Argentine et décrit comment il est devenu une sensibilité hégémonique dans le domaine intellectuel du pays dans les années 1960 et 1970. Pour ça, on a examiné les disciplines, les tendances politiques et les mouvements culturels qui ont mis le tiers-monde au centre des préoccupations.

Mots-clés: tiers-monde; tiers-mondisme; domaine culturel argentin.

Artigo recebido em 12 de janeiro de 2013 e aprovado para publicação em 25 de março de 2013.

[1] Instituto de Estudos Avançados da Universidad de Santiago de Chile - Santiago (Región Metropolitana) - Chile. E-mail: german.alburquerque@usach.cl 

oje, quando se fala em Terceiro Mundo e em terceiro-mundismo, pensa-se em referências já ultrapassadas, próprias do passado; em uma ideologia que, por desconhecer o exemplo dos países desenvolvidos e tentar o caminho oposto, definiu seu destino envolvendo-se em uma crítica insistente e sem propósito contra o capitalismo. Outra visão não confiável do terceiro-mundismo vem do discurso criado pelos países ricos para manter todos os restantes em constante subdesenvolvimento, oferecendo, no fundo, um desenvolvimento somente conveniente aos seus interesses. O que se propõe aqui é uma revisão do conceito de Terceiro Mundo e do pensamento terceiro-mundista em sua dimensão histórica original e em suas raízes latino-americanas.

Embora o conceito tenha nascido na Europa, em 1952, ele prontamente foi apropriado e ressignificado pela África, América Latina e Ásia, adquirindo peso reivindicatório e de identidade, transformando-se finalmente em ideologia. Dentro da área do nosso estudo, a América Latina, concentramo-nos no Cone Sul e, especificamente, na Argentina.

Como e quando foi concebido o terceiro-mundismo na Argentina? Não é fácil averiguar essa informação, pois não existem trabalhos que tenham avançado nesta matéria. Mesmo que o estudo do pensamento argentino tenha se desenvolvido nos últimos anos, ainda há zonas obscuras a serem esclarecidas, especialmente considerando as mudanças trazidas pelas ideias à luz dos pensamentos globais em curso. É assim que, em momentos marcados pelo chamado pensamento único, pelo liberalismo e pela globalização, surgem discursos alternativos colocando em questão tais paradigmas, tentando acabar com a hegemonia ocidental por meio de um retorno cultural baseado em reafirmações locais e no respeito pela diversidade. Neste aspecto, torna-se imperativo revisar discursos e ideologias que, no passado, passaram por encruzilhadas similares e elaboraram saídas ante à prisão dos poderes mundiais, que ameaçavam a autodeterminação e a cultura autóctones.

O terceiro-mundismo foi uma dessas saídas, visto como uma reação não somente contra a Guerra Fria e a sombra estadunidense e soviética que crescia sobre o planeta, mas também contra um processo maior e de ainda mais penetração, o imperialismo. A proposta então é analisar este terceiro-mundismo como uma forma de entender as chaves do debate atual.

A história das ideias na Argentina assumiu o papel de focar no pensamento alternativo. Dentro de uma tradição de estudos que fizeram uma longa análise do pensamento nacional, e que tiveram, dentre seus representantes mais conhecidos Óscar Terán, Carlos Altamirano, Beatriz Sarlo e Arturo Andrés Roig, surgiu o trabalho de Hugo Biagini e do próprio Roig, para narrar o pensamento alternativo na Argentina, liderando equipes de trabalho que, ainda assim, não concluíram seu objetivo. ${ }^{2}$ Convenhamos que a categoria "alternativa" é ambígua e questionável, primeiro porque todo pensamento considerado original deve ser alternativo àquele pré-existente. Para simplificar, Roig demonstrou

${ }^{2}$ Hugo Biagini y Arturo Roig (directores), El pensamiento alternativo en la Argentina del siglo XX, 2 vols., Buenos Aires, Biblos, 2004-2006. 
que o pensamento oficial, ao qual se opõe o alternativo, é aquele dos tiranos da política, dos comerciantes insaciáveis da economia e dos dogmáticos das universidades e igrejas. ${ }^{3}$

Paralelamente, desenvolveu-se nos últimos tempos o que se conhece como opção de descolonização (opção descolonial), sobre a qual os apontamentos de Zulma Palermo são bons indicadores. Com a colaboração tutelar de Walter Mignolo e em sintonia com correntes como as dos estudos pós-coloniais, subalternos e culturais, a descolonização busca emancipar o pensamento e a ciência do centro de gravidade norte-ocidental, que durante séculos foi predominante. Com a necessidade de reconstruir a genealogia da descolonização, Palermo se volta para correntes de ideias que concorreram nessa direção:

\section{Trata-se da produção de um pensamento alternativo ao oficial, de procedência diferente, que vê com clareza o funcionamento do poder, denunciando-o, ainda que seja limitado por pertencer de forma instável ao ocidente. A partir daí é possível desenhar uma linha que vai do pensamento "nacional" aos movimentos de liberação emergentes da teoria da dependência, muitos deles com uma projeção que vai além dos limites nacionais, "através de fronteiras culturais", com efeitos de longa duração em toda a América Latina. ${ }^{4}$}

É justamente nesta linha entre o pensamento nacional e a teoria da dependência que pretendemos posicionar o terceiro-mundismo.

Voltando à pergunta inicial, sobre a fertilidade do campo intelectual argentino ao receber a semente do Terceiro Mundo, apesar das condições favoráveis creio que tal semente tenha germinado com dificuldades. Se compararmos com o Brasil, veremos que neste país o terceiro-mundismo deu frutos com mais força e rapidez, por vários motivos, e o primeiro deles é a semelhança cultural, étnica e até geográfica com a África. ${ }^{5}$ No plano das ideias, havia sintonia devido à presença do nacionalismo anti-imperialista, vinculado ao Instituto Superior de Estudos Brasileiros (ISEB) e, mais remotamente, ao populismo de Getúlio Vargas. Além disso, nos anos 1950, um grupo de estudiosos das relações internacionais ligado a trabalhos diplomáticos questionou precocemente a possibilidade de dialogar com os continentes periféricos. Assim, o terceiro-mundismo se propagou em várias disciplinas, e supôs uma sensibilidade preeminente, com poucas vozes discordantes. Na Argentina também existia uma linha de pensamento aparentemente bem disposta para o Terceiro Mundo, porém, apesar disso, só decolou na segunda metade da década de 1960.

\footnotetext{
${ }^{3}$ Arturo Roig, "A manera de prólogo. Hacia una acotación teórico-crítica del pensamiento alternativo como esperanza”, In: Hugo Biagini y Arturo Roig (directores), El pensamiento alternativo en la Argentina del siglo XX. Tomo Il: Obrerismo, vanguardia, justicia social (1930-1960), Buenos Aires, Biblos, 2006, p. 11-12.

${ }^{4}$ Zulma Palermo, "Introducción. Del pensamiento nacional a la opción descolonial: aportes desde el Cono Sur", In: ___ (comp.), Pensamiento argentino y opción descolonial, Buenos Aires, Ediciones del Signo, 2010, p. 36. O sublinhado é do autor deste artigo.

5Véase Germán Alburquerque, "Tercer Mundo y tercermundismo en Brasil: hacia su constitución como sensibilidad hegemónica en el campo cultural brasileño - 1958-1990”, Estudos Ibero-Americanos, v. 37, n. 2. Porto Alegre, 2011, p. 176-195.
} 
Objetivamente, o sentido deste trabalho é demonstrar que o terceiro-mundismo se instalou na Argentina e se disseminou largamente pelo campo intelectual do país, transformando-se em sensibilidade hegemônica. Entendemos o terceiro-mundismo em um sentido amplo, ou seja, como ideologia, sensibilidade e paradigma. Como ideologia, configura-se em um conjunto coerente de ideias sobre as realidades nacional e internacional, que comporta uma explicação ou diagnóstico da mesma e uma estratégia para transformá-la. O terceiro-mundismo só se qualifica como ideologia se considerarmos o significado flexível da palavra. Nesse sentido, deve-se reconhecer que não se trata de um conjunto sistemático e imutável, como poderia ser o socialismo, o marxismo ou o liberalismo, mas sim de declarações dispersas que faziam parte de outras linhas de pensamento. Em termos de sensibilidade, referimo-nos a uma determinada atitude frente à sociedade, uma disposição positiva ou negativa em relação a referenciais políticos, econômicos, culturais, religiosos etc., a qual se traduz em opiniões, tomadas de decisão, gostos, preferências e interesses, integrando elementos emotivos e subjetivos. Como paradigma, referimo-nos a um modo particular de conhecer a realidade com base em preceitos teóricos e procedimentos metodológicos. Embora o terceiro-mundismo tenha gerado elementos que avançavam nesta direção, não conseguiu expressar um paradigma rigoroso e compacto. Consequentemente, seria mais apropriado falar de um pré-paradigma ou de um paradigma frágil.

O terceiro-mundismo se propagou em várias
disciplinas, e supôs uma sensibilidade preeminente,
com poucas vozes discordantes

Nesta oportunidade, vamos nos dedicar à segunda dimensão do terceiro-mundismo, a sensibilidade (que também contém aspectos ideológicos e de paradigma), uma sensibilidade hegemônica porém não excludente ao interior do campo intelectual argentino. Se entendermos como campo o espaço onde circulam e se relacionam - estabelecendo supremacias, oposições, cumplicidades, neutralidades etc. — as forças (tendências ideológicas, paradigmas científicos, correntes artísticas, estéticas), os bens simbólicos (obras artísticas e científicas, discursos, manifestos) e os atores (individuais, coletivos ou institucionais), percebemos que o terceiro-mundismo se fez presente em todas essas dimensões (neste sentido, é hegemônico), porém, em sintonia com outras sensibilidades, como o liberalismo, o anti-imperialismo, o dependentismo, o revolucionarismo, ou, em termos mais globais, o esquerdismo. Em outras palavras: no campo intelectual argentino dos anos 1960 e 1970, predominou uma sensibilidade de esquerda, e dentro dela é possível reconhecer outras mais limitadas, como o terceiro-mundismo e outras mencionadas. 


\section{O campo intelectual argentino: décadas de 1950 e 1960}

Até a metade do século, é possível reconhecer na Argentina uma tradição de estudos político-sociais dedicados à denúncia do imperialismo e à luta por uma soberania autêntica. Pensadores como Raúl Scalabrini Ortiz, Arturo Jauretche, Juan José Hernández Arregui, Jorge Abelardo Ramos ou Rodolfo Puiggrós foram reconhecidos, nos anos 1950, como expoentes de um nacionalismo que, em alguns casos, envolvia instrumentos de análise do marxismo, mesmo que sem dogmatismos. ${ }^{6}$ Outro grupo, mais ou menos contemporâneo, elaborou uma reflexão profunda sobre a existência e a identidade dos argentinos, partindo de uma postura telurista, como a de Ezequiel Martínez Estrada, ou a partir de uma busca mais existencialista, como a de Héctor Alvarez Murena ou Rodolfo Kusch, promovendo um ensaio determinista ou essencialista, com base em uma interpretação "ontológico-intuicionista" da realidade. ${ }^{7}$

Mesmo que ambos os grupos tenham publicado conteúdo de igual ou maior importância, rapidamente tiveram de compartilhar o campo com novas gerações de cientistas sociais com perfis mais profissionais. ${ }^{8}$ Economistas, sociólogos e cientistas políticos surgiram no campo cultural argentino, modificando a linguagem - menos retórica e mais técnica - , dialogando com o estrangeiro muitos estudavam fora - , ampliando o horizonte temático e tentando intervir na condução do país - estão mais próximos do establishment. Consideremos, por exemplo, Raúl Prebisch, economista que preside o Banco Central e elabora uma obra acadêmica de projeção internacional, inclusive antes da fundação da Comissão Econômica para América Latina e o Caribe (CEPAL), ou o ítalo-argentino Gino Germani, que promoveu a profissionalização da sociologia, o conhecimento de escolas e autores europeus e norteamericanos, a incorporação e a aplicação de métodos científicos estrangeiros, ou seja, o salto para uma ciência social modernizante disposta a mudar a sociedade. ${ }^{9}$

Nos anos 1960, então, ocorreu uma grande eclosão que se manifestou com a proliferação de revistas político-culturais, com a fertilidade editorial e com o surgimento de centros culturais, como o Instituto di Tella ou o Instituto de Desarrollo Económico y Social (IDES) ${ }^{10} \mathrm{O}$ fenômeno se enraizou em fatores externos e internos. As notícias provenientes de Cuba levaram à convicção de que a revolução era possível na América Latina e que, inclusive, podia adotar

\footnotetext{
"Hugo Chumbita, "Patria y revolución: la corriente nacionalista de izquierda”, In: Hugo Biagini y Arturo Roig (directores), El pensamiento alternativo en la Argentina del siglo XX, vol. 2, Buenos Aires, Biblos, 2006; Oscar Terán, Historia de las ideas en la Argentina: Diez lecciones iniciales, 1810-1980, Buenos Aires, Siglo XXI, 2008. 7Oscar Terán, op cit., p. 267.

8Para Terán, "isso aconteceu ao disputar o espaço do ensaio de interpretação ontológico-intuicionista dominante desde a década de 1930. Agora, o estudo da sociedade devia ser científico como condição de neutralidade, e deveria incluir uma análise valorativa, distante de toda ideología, inclusive em termos de política, ou deveria compreender uma forte impregnação político-social." - Oscar Terán, op cit., p. 277.

${ }^{9}$ Alejandro Blanco, Razón y modernidad: Gino Germani y la sociología en la Argentina, Buenos Aires, Siglo XXI, 2006. Em sua grande obra, Germani se ocupou do Terceiro Mundo tangencialmente em "¿Pertenece América Latina al Tercer Mundo?", Aportes, n. 10, Buenos Aires, octubre de 1968.

${ }^{10} \mathrm{O}$ que ocorre nas universidades é ambivalente. Por um lado, elas se beneficiam do auge das ciências sociais e da extensão da matrícula; por outro, a autonomia fica debilitada frente a um poder político que, no caso, não deixa de intervir nos locais de estudo.
} 
sua própria fisionomia, alheia aos moldes teóricos. Em plena Guerra Fria, o interesse dos Estados Unidos pela América Latina motivou o financiamento da investigação científica e a criação artística. Os organismos internacionais CEPAL, Facultad Latinoamericana de Ciencias Sociales (FLACSO) e Consejo Latinoamericano de Ciencias Sociales (CLACSO) - deram vida às ciências sociais. Internamente, os conflitos políticos e a questão peronista levaram os intelectuais a terem um crescente compromisso ideológico.

\author{
Muitas editoras iniciaram coleções relativas ao \\ Terceiro Mundo, por exemplo, Libros para el Tercer \\ Mundo; Problemas latino-americanos y del \\ Tercer Mundo; Biblioteca de Asia y Africa, de \\ Eudeba; Tercer Mundo
}

Sabe-se que, frente ao governo de Juan Domingo Perón, os escritores e intelectuais assumiram posições diversas. Vários deles o apoiaram - como os já mencionados Jauretche, Scalabrini, Hernández Arregui ou Puiggrós -, enquanto outros, a maioria deles, repudiaram-no ou se mostraram céticos. Depois da saída de Perón, em 1955, as coisas começaram a mudar. O movimento social foi valorizado, separando-se da figura de Perón, e passou-se a considerar o peronismo como uma possibilidade real de emancipação popular. Desta maneira, tomou corpo a "nova esquerda", concebida como uma superação dos partidos tradicionais, o comunista e o socialista, que se organizou com base em princípios básicos, originando o que Sigal chamou de "unificação ideológica". ${ }^{11}$ A intelectualidade - em termos gerais — passou a ser anti-imperialista (e nacionalista) e revolucionária, apoiando o movimento popular (pretendia se aproximar ou pertencer ao povo) e a luta anticolonial (vocação, digamos, terceiro-mundista). Por fim foi, em maior ou menor grau, marxista. ${ }^{12}$

\footnotetext{
"Silvia Sigal, Intelectuales y poder en la década del sesenta, Buenos Aires, Puntosur, 1991, p. 193. Nesta obra, Sigal reconhece a onda do terceiro-mundismo que percorreu a Argentina nos anos sesenta e que alcançou um "estado de horror nas publicações intelectuais. O progressismo argentino nunca tinha estado fechado ao exterior, porém, antes de 1960, seu interesse era voltado particularmente a episódios ligados à dominação norteamericana na América Latina. Agora, por sua vez, estão atentos a movimentos nacionalistas ou revolucionários em países que eran, até então, praticamente desconhecidos para os argentinos" (p. 193). 12Sobre intelectuais e ciências sociais na Argentina do período: Oscar Terán, Nuestros años sesentas, Buenos Aires, Puntosur, 1991; Silvia Sigal, op cit; Beatriz Sarlo, La batalla de las ideas (1943-1973), Buenos Aires, Emecé, 2007; Bibiana G. García, Las ciencias sociales y el pensamiento crítico: ideas, prácticas e instituciones en el campo de la sociología latinoamericana de Brasil y Argentina, Documento CLACSO-Argentina, 2007; José Luis de Diego, "Los intelectuales y la izquierda en la Argentina (1955-1975)", In: Carlos Altamirano (ed.), Historia de los intelectuales en América Latina II: Los avatares de la "ciudad letrada" en el siglo XX, Buenos Aires, Katz, 2010, p. 395-416; Pablo Ponza, "Comprometidos, orgánicos y expertos: intelectuales, marxismo y ciencias sociales en Argentina (1955-1973)", A Contra corriente, vol. 5, n. 2, 2008, p. 74-98; Ana María Barletta y María Laura Lenci, "Politización de las Ciencias Sociales en la Argentina. Incidencia de la revista Antropología 3er. Mundo 1868-1973", Sociohistórica, n. 8, La Plata, 2001, p. 177-199; Anabela Ghilini, "Sociología y liberación nacional: la experiencia del grupo universitario de las 'Cátedras Nacionales”', Question, vol. 1, n. 29, La Plata, 2011, p. 1-14.
} 
A seguir, revisaremos em paralelo e separadamente as etapas dos processos: primeiramente, o modo como o terceiro-mundismo se demonstrou por várias dimensões; em segundo lugar, a forma como o terceiro-mundismo amadureceu e alcançou solidez conceitual.

\section{Primera etapa: início e expansão do terceiro-mundismo argentino (1961-1967)}

No cenário politizado e radical recém-desenhado chegou o terceiro-mundismo, o que ocorreu um pouco tarde, em 1961. Poderia ter sido antes se os pensadores nacionais e anti-imperialistas da década de 1950 tivessem empregado o conceito, já que a estrutura de suas ideias coincidia com o enfoque terceiro -mundista (pode-se dizer que foram terceiro-mundistas sem saber disso ou, em outras palavras, pré-terceiro-mundistas). É o caso, por exemplo, de Arturo Frondizi, que já em 1955 evocava a Conferência de Colombo, uma das raízes do Não-Alinhamento (conceito parecido, porém, não idêntico ao Terceiro Mundo, ainda que alguns não o tenham entendido assim); ${ }^{13}$ ou o de Abraham Guillén, que anunciava, com tom entusiasmado, o fim do imperialismo; ${ }^{14}$ ou o de Hernández Arregui, para quem a "rebeldia das colônias na Ásia e na África, assim como a instabilidade crescente da América Latina, favoreceram a luta pela liberação nacional, que, por sua vez, é parte da política mundial"; ${ }^{15}$ ou o de Ezequiel Martínez Estrada, que reconhecia a maior afinidade cultural com a África do que com a Europa. ${ }^{16}$ Algo interessante ocorreu com Rodolfo Puiggrós, pois ele defendia um novo internacionalismo que "vai sendo criado de baixo para cima, na coincidência dos povos que se desalienavam de ideologias fetichistas e de sistemas opressivos". ${ }^{17}$ Não o chama de Terceiro Mundo, porém, o autor do prólogo o faz, o mexicano Álvaro de Faría. ${ }^{18}$ Estamos em 1965 e por algum motivo Puiggrós ignorou o conceito. Não o conhece ou resiste em utilizá-lo?

O certo é que não há menções explícitas ao Terceiro Mundo. Naquela época a palavra já era conhecida, e até utilizada pela imprensa ou no âmbito das relações internacionais, porém, em textos acadêmicos e intelectuais isso não ocorreu até que o historiador e ensaísta Sergio Bagú, em um texto sobre a situação argentina no cenário internacional, não somente "introduziu" o Terceiro Mundo, como também decretou que seu país pertencia a ele:

Frente a ambos os tipos de prosperidade econômica [soviética e ocidental], o Terceiro Mundo - a imensa faixa de subdesenvolvimento

\footnotetext{
${ }^{13}$ Arturo Frondizi, La lucha antiimperialista: etapa fundamental del proceso democrático en América Latina, Buenos Aires, Debate, 1955, p. 70.

${ }_{14}^{14}$ Abraham Guillén, La agonía del imperialismo, vols. 1 y 2, Buenos Aires, Sophos, 1956-1957.

15Juan José Hernández Arregui, La formación de la conciencia nacional (1930-1960), Buenos Aires, Hachea, 1960, p. 450.

${ }^{16}$ Ezequiel Martínez Estrada, Diferencias y semejanzas entre los países de la América Latina, Caracas, Biblioteca Ayacucho, 1990 (1962)

17Rodolfo Puiggrós, Integración de América Latina, Buenos Aires, Jorge Álvarez Editor, 1965, p. 80.

${ }^{18} / \mathrm{dem}$, Ibidem, p. 16. De Faría aboga por la integración regional como primer paso de la unión global del Tercer Mundo.
} 
e do subconsumo a qual pertence a Argentina - encontra-se em um período crítico, com seus índices de crescimento econômico pouco acima ou bem abaixo dos índices de crescimento demográfico. ${ }^{19}$

Seja como for, nesta tímida primeira etapa é claro que o terceiro-mundismo não é de uso corrente, ainda que uma predisposição positiva já seja observada.

A partir de 1964, o terceiro-mundismo começou a se firmar e a se propagar. Neste ano surgiu o livro assinado pela Logia ANAEL ${ }^{20}$ e o artigo de Héctor Schmucler. ${ }^{21}$ No ano seguinte circularia a revista La Voz del Tercer Mundo, que, em sua apresentação, escrita pelo diretor Diógenes Garibaldi, expressava os motivos para associar de imediato o Terceiro Mundo ao Não-Alinhamento, e celebrava que a política de blocos e os interesses do imperialismo e do colonialismo tivessem enfrentado ainda um contrapeso:

Felizmente esta situação chega ao fim. Os povos em desenvolvimento [...] uniram-se para formar não um novo bloco, mas um verdadeiro mundo próprio: o Terceiro; aquele do não-alinhamento [...]..22

Não há mais registros desta breve publicação, que mesmo com publicidade e levada ao comércio exterior, poderia dar sinais sobre uma política de aproximação cultural com tendência a estreitar vínculos de mercado. Como veremos, esta seria só a primeira de quatro revistas que levaram em seu nome o conceito de Terceiro Mundo.

$\mathrm{O}$ auge do terceiro-mundismo também se refletia na indústria editorial. Muitas editoras iniciaram coleções relativas ao Terceiro Mundo, por exemplo, Libros para el Tercer Mundo; Problemas latino-americanos y del Tercer Mundo; Biblioteca de Asia y Africa, de Eudeba; Tercer Mundo, da Editorial Sur. Da mesma forma, circularam os Guias do Terceiro Mundo, publicações que informavam sobre os detalhes dos países periféricos; na mesma linha havia obras como Hechos del Tercer Mundo e Hombres del Tercer Mundo, dentro da série Transformaciones en el Tercer Mundo, do Centro Editor de América Latina. Tudo indica a existência de um público relativamente grande interessado no tema, e isso mostra que, definitivamente, o ambiente estava preparado para a época de maior interferência do Terceiro Mundo no campo cultural argentino.

\section{Segunda etapa: esplendor e maturidade (1968-1974)}

A difusão do terceiro-mundismo na Argentina neste período ocorreu de tal modo que alcançou esferas em princípio alheias a um conceito e uma ideologia, identificadas como política internacional e desenvolvidas por cientistas sociais. São estas esferas que emplacaram, em última instância, a constituição do terceiro-mundismo em sensibilidade hegemônica.

\footnotetext{
19 Sergio Bagú, Argentina en el mundo, Buenos Aires, FCE, 1961, p. 175.

${ }^{20}$ Logia ANAEL, La razón del Tercer Mundo, Buenos Aires, 1964.

${ }^{21}$ Héctor Schmucler, "Problemas del Tercer Mundo”, Pasado y Presente, n. 4, Córdoba, 1964

22“"Nuestra misión y su alcance”, La voz del Tercer Mundo, n. 1, Buenos Aires, 1965, p. 1.
} 
Não é de se surpreender, no entanto, que o terceiro-mundismo penetrava em expressões artísticas de alta importância social, como o cinema, mesmo considerando o precedente do Brasil, onde o cineasta Glauber Rocha tinha filmado e criado teorias sobre o Terceiro Mundo em sua mente. Na Argentina, um acontecimento como a Segunda Reunião do Comitê de Cinema do Terceiro Mundo, organizada pelo Instituto del Tercer Mundo da Universidad de Buenos Aires, em 1974, marcou a força de uma tendência que havia visto seus primeiros frutos muito antes. Octavio Getino e Fernando Solanas realizaram o documentário La hora de los hornos (1968) inspirados por uma vocação terceiro-mundista e anti-imperialista. Em 1969, eles redigiram um documento no qual anunciaram o nascimento de um Terceiro Cinema:

A luta anti-imperialista dos povos do terceiro mundo e de seus semelhantes no seio de suas metrópoles constitui hoje o olho da revolução mundial. Terceiro cinema é, para nós, aquele que reconhece nesta luta a maior manifestação cultural, científica e artística do nosso tempo, a grande possibilidade de construir, a partir de cada povo, uma personalidade liberal: a descolonização da cultura. ${ }^{23}$

O Movimento de Sacerdotes para o Terceiro Mundo levou à outra manifestação da sensibilidade terceiro-mundista, a qual se disseminou pela Argentina dos anos 1960 e 1970. Ela se originou de um célebre manifesto de bispos do Terceiro Mundo - com a presença e liderança de religiosos brasileiros, liderados por Helder Câmara —, o qual, em 1967, teve grande repercussão na opinião pública internacional. Ainda que tivesse a presença de centenas de integrantes, nunca adotou institucionalidade formal, mas foi se definindo com o tempo, até que o nome apareceu na imprensa. Sua principal preocupação foi a realidade política argentina e, neste contexto, emitiu muitas declarações, respondendo de forma geral sob uma perspectiva de esquerda, liberacionista e peronista. Certamente também visava o exterior, e inseria a evolução nacional na luta tricontinental. Em 1969, em um documento anunciado em Córdoba, intitulado Nuestras coincidências básicas, explicitava sua noção de Terceiro Mundo:

Uma realidade inegável: a existência de países (sobretudo na Ásia, África e América Latina), e de setores dentro de todos os países, que padecem de uma situação de injustiça, oprimidos por uma situação e vítimas das sequelas da fome, analfabetismo, insegurança, marginalização etc. Realidade que se convencionou chamar de terceiro mundo [...] Uma tomada de posição: nós, homens cristãos e sacerdotes de Cristo, [...] sentimo-nos solidários por esse terceiro mundo e servidores de suas necessidades. ${ }^{24}$

${ }^{23}$ Octavio Getino y Fernando Solanas, "Hacia un tercer cine. Apuntes y experiencias para el desarrollo de un cine de liberación en el Tercer Mundo", Hojas de cine: testimonios y documentos del nuevo cine latinoamericano, México, UAM, 1988 (1969), p. 33-34.

${ }^{24}$ Em Gabriel Seisdedos, Hasta los oídos de Dios: la historia de los Sacerdotes del Tercer Mundo, Buenos Aires, San Pablo, 1999, p. 84. 
O surgimento do terceiro-mundismo no âmbito da psicologia foi um pouco mais ousada. Óscar Calvo ocupou-se da dinâmica grupal, técnica terapêutica e educativa que, importada dos países centrais, foi aceita com entusiasmo no Terceiro Mundo. Porém, Calvo viu na dinâmica grupal clássica uma das tantas armas de dominação cultural do imperialismo, que operava anestesiando as possibilidades críticas, distraindo a práxis e movendo forças de grupo para realizar o reformismo institucional. Ao evocar a pedagogia libertadora do brasileiro Paulo Freire, apostava em uma dinâmica conscientizadora que negava a anterior, "assumindo seus objetivos limitados, porém, sempre válidos, movendo-os com os 'você existe para quê', que todo um Terceiro Mundo saqueado e menosprezado lança a qualquer grupo humano, opressor e oprimido".25

Para os cientistas sociais terceiro-mundistas,
a rebelião causada pelo colonialismo trazia a
necessidade de adequar a teoria e a metodologia a
este movimento e, consequentemente, abandonar os
paradigmas da ciência ocidental

Mas o terceiro-mundismo conquistaria um terreno verdadeiramente excêntrico em sua face esotérica. A Logia ANAEL, de origem e trajetória misteriosas, começa com o caminho terceiro-mundista, se dermos crédito ao já mencionado La razón del Tercer Mundo (1964), ${ }^{26}$ desde 1956, em São Paulo. Nesta cidade, o Doutor Anael, também de perfil obscuro, reuniu-se com representantes latino-americanos e afroasiáticos, estabelecendo os alinhamentos com o foco na elevação do Terceiro Mundo. Para alcançar isso, a Logia confiava em Perón e no brasileiro Ademar de Barros. ${ }^{27}$ A Logia e o peronismo estavam conectados por José López Rega, homem ligado a Perón e à Estela Martínez que, nos anos 1970, tornaria-se ministro. ${ }^{28} \mathrm{O}$ plano era que Brasil e Argentina convertessem a América do Sul em uma única grande federação, e desta maneira formassem, no mapa, uma letra "L" inclinada (Lima-Buenos Aires- São Paulo) que, por sua vez, corresponderia aos vértices do triângulo escaleno do triplo A (iniciais de América, África e Ásia):

O primeiro Vértice - Pequim - está possibilitando que os povos do Terceiro Mundo iniciem a marcha de sua liberação. A consolidação do segundo - Argélia - acelerará a marcha. Quando os três atuarem paralelamente, as estruturas imperialistas começarão a se enfraquecer por toda parte..$^{29}$

\footnotetext{
${ }^{25}$ Oscar Calvo, Dinámica grupal para el Tercer Mundo, Buenos Aires, Ediciones Paulinas, 1973, p. 21. ${ }^{26}$ Logia ANAEL, La razón del Tercer Mundo, Buenos Aires, 1964.

${ }^{27}$ Governador de São Paulo e candidato à presidência.

${ }^{28}$ Ver Ernesto Milá, La vertiente ocultista del peronismo. La Logia Anael, Disponible en: <http://infokrisis.blogia. com>, Acceso en 22 de septiembre de 2012.

${ }^{29}$ Logia ANAEL, El Tercer Mundo en acción. La estructura latinoamericana, Buenos Aires, 1965, p. 8.
} 
Em 1974 a Logia reforçava o aspecto espiritual que guiava a ação dos analistas, pois anunciava a chegada de um novo homem social libertado, o homem Moral. ${ }^{30}$ Porém, as boas intenções se acabariam na Aliança Anticomunista Argentina, a famosa Triplo A (sigla já mencionada), grupo paramilitar de extrema direita vinculado a López Rega que espalhou o terror pela Argentina dos anos $1970 .{ }^{31}$

O terceiro-mundismo expandia suas fronteiras com o cinema, a religião, a psicologia, o esoterismo; sem dúvida, estas expressões não propunham um aprofundamento da elaboração conceitual de Terceiro Mundo. A ela nos dedicaremos a seguir, anunciando que se desenvolveu fundamentalmente no plano político-ideológico, com a contribuição de revistas militantes, das ciências sociais - que também abordavam problemas epistemológicos - e de atores políticos específicos. O terceiro-mundismo alcançou sua maturidade no calor dessas discussões, com a produção das ideias originais que constituíram, finalmente, uma ideologia. ${ }^{32}$

Tanto a Revista de Problemas do Terceiro Mundo como a Antropología 3er Mundo contrastaram com a renomada La voz del Tercer Mundo ao mostrar uma linha editorial mais comprometida e discursiva. ${ }^{33}$ A primeira tinha uma equipe editorial de peso, com reconhecidos intelectuais de esquerda, os quais, em parte, tinham dado vida à Contorno, importante publicação dos anos $1950 .{ }^{34}$ No editorial da primeira edição colocava sua posição ideológica: "A segurança na necessidade de contribuir com o fim de um sistema, o capitalismo em sua face imperialista, que já perdeu globalmente todo o aspecto positivo para, hoje, ser somente uma força opressora e destrutiva, até onde aparentemente é benigno". ${ }^{35}$ Considerava um dever evidenciar "os vínculos de nossa batalha nacional com o conjunto das lutas imperialistas que acontecem no mundo", ${ }^{\prime 36}$ assim como esclarecer enfaticamente que a luta contra o imperialismo não excluía a opção revolucionária pelo socialismo, caminho obrigatório uma vez terminada a dependência: "Nenhuma excepcionalidade histórica coloca as sociedades do Terceiro Mundo à margem da dialética das classes" ${ }^{37}$ Como veremos, esta declaração remeteu à discussão mais fervorosa sobre o terceiro-mundismo argentino, sobre a centralidade das classes em relação à nação e ao povo.

\footnotetext{
30 Julio César Urién, El camino del hombre: La liberación del Tercer Mundo, Buenos Aires, ANAEL, 1973, p. 402. ${ }^{31}$ Podemos mencionar outros conflitos não tradicionais. Marcos Aguinis fez uma exploração original em La cuestión judía vista desde el Tercer Mundo, Buenos Aires, Librería Superior, 1974. Também, ainda que anos mais tarde, Alcira Argumedo se referiu, a partir de uma perspectiva terceiro-mundista, ao problema tecnológico e, mais precisamente, às comunicações em Los laberintos de la crisis. América Latina: poder transnacional y comunicaciones (1984), citado por Susana Barbosa, "Sobre la dependencia tecnológica: Alcira Argumedo", Juan Carlos Agulla, Ideologías políticas y ciencias sociales, Buenos Aires, Academia Nacional de Ciencias de Buenos Aires, 1996.

32 Sobre o problema, podemos considerar o terceiro-mundismo argentino como uma idelogia, e dedicou outro trabalho, , "La ideología del Tercer Mundo en Argentina. 1961-1977”, Inédito.

${ }^{33}$ Finalmente, a Revista Tercer Mundo surgiu em 1974, ainda que com um padrão mais de divulgação do que de declaração. Somente os primeiros números foram editados na Argentina. A partir de 1976 seu diretor, Pablo Piacentini, exilou-se no México, de onde continuou a produzir a revista, rebatizada de Cuadernos del Tercer Mundo.

${ }^{34}$ Observam-se os nomes de Roberto Cossa, Ricardo Piglia, David e Ismael Viñas, Roberto Walsh, Francisco Urondo, Raúl Sciarreta, León Rozitchner, Jorge y Andrés Rivera e Juan Carlos Portantiero.

35“"Editorial”, Revista Problemas del Tercer Mundo, n. 1, Buenos Aires, 1968, p. 3.

36"Por qué Tercer Mundo", Revista Problemas del Tercer Mundo, n. 2, Buenos Aires, 1968, p. 83.

${ }^{37}$ Idem, Ibidem, p. 84.
} 
Até o momento, mediando esta polémica, nasceria a Antropología 3er Mundo, talvez a mais consistente das revistas mencionadas, tanto por sua persistência no tempo, de 1968 a 1973, quanto pela coerência de suas publicações. Trabalho de um grupo de acadêmicos da Faculdade de Filosofia e Letras da Universidade de Buenos Aires, com explícita orientação peronista de esquerda, a revista defendia, em oposição ao marxismo clássico, que o único internacionalismo viável era aquele que unia os povos dependentes e lutava por sua libertação, e não a comunhão das classes proletárias de países ricos e pobres, qualificadas como abstração sem sentido. Porém, também não pretendia uma terceira via entre o capitalismo e o socialismo, apostando em uma saída de esquerda que iria requerer, sem dúvida, a soma de todos os esforços.

\begin{abstract}
A afirmação de um Terceiro Mundo implica tanto na existência de um campo diferenciado dentro do jogo de blocos internacional, como em um caminho rumo ao fim da dependência: a unificação dos povos que compõem o Terceiro Mundo em um bloco solidário, em luta pela libertação nacional e social, é o caminho efetivo para alcançar o fim da dominação. ${ }^{38}$
\end{abstract}

As ciências sociais foram influenciadas pelo terceiro-mundismo, e este também foi influenciado pelas ciências sociais argentinas. Foi, sem dúvida, uma relação dialética de mútuo enriquecimento. Logicamente, foram os cientistas sociais argentinos que deram as boas-vindas ao Terceiro Mundo, devido ao caráter econômico e geopolítico original do conceito. Por isso, a aproximação que aconteceu foi menos "científica" que no Brasil, onde muitas disciplinas assumiram o Terceiro Mundo segundo sua perspectiva teórico-metodológica particular. Na Argentina, o tratamento foi mais político e ensaísta, com mediação disciplinar fraca. Aqueles que teorizaram sobre o Terceiro Mundo se esforçaram para desenvolver uma interpretação a partir de seus pressupostos políticos ou ideológicos, mas além disso pessoalmente foram efetivamente profissionais de sociologia, economia, antropologia, história, política ou psicologia.

O Terceiro Mundo idealizado pelas ciências sociais argentinas, especialmente para a sociologia, foi um catalizador que acabou com seus princípios. Ao mesmo tempo, permitiu que elas elaborassem uma resposta ao cientificismo que era forte nas universidades. Para os cientistas sociais terceiro-mundistas, a rebelião causada pelo colonialismo trazia a necessidade de adequar a teoria e a metodologia a este movimento e, consequentemente, abandonar os paradigmas da ciência ocidental. Roberto Carri expressava: "reivindicamos um conhecimento singular ou particular sobre a expressão da luta anti-imperialista dos povos do Terceiro Mundo, especialmente das maiorias argentinas".39 Gonzalo Cárdenas, no entanto, analisou a necessidade de renovação:

Uma nova corrente sociológica que aborde problemas nacionais e latino-americanos, e que busca sua correlação com outros

38"La idea de la revista Antropología 3er mundo", Antropología 3er mundo, n. 2, Buenos Aires, 1969, p. 2.

${ }^{39}$ Roberto Carri, "El formalismo en las ciencias sociales (2a parte)", Antropología 3er Mundo, n. 2, Buenos Aires, 1969, p. 63 
fenômenos da Ásia e da África (lutas sociais contemporâneas) vai superar a versão da sociologia tradicional. ${ }^{40}$

Carlos Mastrorilli pedia diretamente uma mudança de paradigma: "Assim como Galileu e Colón impuseram a revisão da ciência no Ocidente, o Terceiro Mundo também deve provocar a imprescindível adequação ideológica no centro". 41

Tratava-se de formular uma ciência a serviço da libertação, que encontrasse na mesma luta as chaves do conhecimento. Da luta revolucionária derivariam, de forma nunca explicitada, os elementos fundamentais. ${ }^{42} \mathrm{~A}$ ciência social do Terceiro Mundo se apresenta como fruto de um esforço mais voluntário do que autenticamente epistemológico. Contudo, é evidente que o Terceiro Mundo serviu de pivô para novos conceitos que entenderam que a verdadeira libertação também necessitava de uma ciência própria, separando-se daquela do centro, qualificada como cúmplice do imperialismo.

\section{"A luta revolucionária é uma só no mundo todo, havendo condições objetivas para a solidariedade dos oprimidos do Primeiro, Segundo e Terceiro Mundo"}

O terceiro-mundismo não era uma ideologia excludente; pelo contrário, podia coexistir harmonicamente com as outras. Desde quando o Terceiro Mundo propôs uma reivindicação que buscava a subversão da ordem existente e a superação da desigualdade econômica, o terceiro-mundismo tornou-se um pensamento de esquerda e, como tal, dialogou com o comunismo, o marxismo, o anti-imperialismo, o populismo, o socialismo e suas variantes. No

\footnotetext{
${ }^{40}$ Gonzalo Horacio Cárdenas, "La sociología neocolonialista en la Argentina”, Ciencias sociales: ideología y realidad nacional, selección de Rosalía Cortés, Buenos Aires, Editorial Tiempo Contemporáneo, 1970, p. 140. ${ }^{41}$ Carlos Mastrorilli y Fernando Álvarez, Marcuse, Sartre, Nizan, Gorz y el Tercer Mundo, Buenos Aires, Carlos Pérez Editor, 1969, p. 22.

${ }^{42}$ Este novo paradigma não foi invenção exclusiva da Argentina, mas também se desenvolveu em outros espaços, destacando a figura do colombiano Orlando Fals Borda, que identificava uma reversão na transmissão geral do conhecimento: agora seria o Sul a ensinar o Norte o caminho epistemológico. Seguindo esta linha, o argentino Pedro Negre Rigol apostava em uma sociología de libertação: "A sociologia da mudança no Terceiro Mundo desemboca, por fim, na teoria da revolução, que implica no desenvolvimento e na libertação [...] A teoria ou teorias revolucionárias não são formuladas no abstrato [...] Debe-se buscar sua formulação em um nível mais concreto, com uma série de perguntas de tipo analítico: quem são os sujeitos da revolução? Quais são os obstáculos? Que condições existem? Como acontece o trânsito ideológico da libertação nacional e da libertação da América Latina, do Terceiro Mundo e do mundo?" - Sociología del Tercer Mundo, Buenos Aires, Paidós, 1975, p. 133-134.
} 
território argentino, este diálogo incluiu, também, o peronismo, o dependentismo ${ }^{43}$ e o liberacionismo. ${ }^{44}$

A corrente com a qual mais se relacionou o terceiro-mundismo foi o "socialismo nacional", um socialismo que combinava a socialização dos meios de produção, a estatização e a ruptura radical com as metrópoles. Se a isso se somar o anti-imperialismo - quase onipresente na política do período - e a exaltação da solidariedade com os povos da África e da Ásia, veremos que o socialismo nacional se transforma em terceiro-mundismo. Segundo Eduardo Astesano,

o socialismo nacional aponta para uma internacionalização libertadora terceiro-mundista, que busca a socialização mundial dos meios de produção para superar a desigualdade nacional e o subdesenvolvimento. ${ }^{45}$

Como é possível observar, o socialismo nacional escondia um internacionalismo radical, o que foi interpretado como algo contraditório, porém, que encontrava sentido ao pensar nos conceitos chave de povo, nação e classe e, finalmente, no marxismo, com o qual criou polêmica. Para o terceiro-mundismo, o protagonismo histórico retornava aos povos dos continentes periféricos que lutavam pela libertação total do colonialismo. Esses povos e nações - conceitos que podem ser semelhantes - deveriam unir seus esforços para assegurar o fim da dependência, cobrando, desta forma, o internacionalismo. A luta nacional, portanto, era prioritária em relação à de classes, porém, o terceiro-mundismosocialista-nacional não se esqueceu desta, pois acreditava que, uma vez consumada a libertação nacional, as classes proletárias deviam conduzir o processo.

Confirmava-se que o etapismo marxista perdia a validade, pois os fatos demonstravam o contrário:

[Os povos do Terceiro Mundo], com suas lutas, manifestaram que não há evolução de um todo social unitário, nem a superioridade

\footnotetext{
${ }^{43} \mathrm{~A}$ teoria da dependência foi bem aceita na Argentina, e mesmo que não tenha producido criadores muito relevantes, conseguiu posicionar o dependentismo na linguagem cotidiana. Com o terceiro-mundismo, teve relações estreitas e quase nunca contraditórias, ainda que seja importante apontar que o dependentismo teve um caráter mais teórico, enquanto o terceiro-mundismo fazia uma aplicação mais direta de seus planejamentos com a realidade histórica e contingente dos continentes periféricos.

${ }^{44}$ Liberacionismo e terceiro-mundismo em geral fizeram uma grande troca, e perfeitamente era possível apreciar um ou outro. Esta corrente ganhou notável força na Argentina, sobretudo com a filosofía da libertação, que praticamente nascia neste país. O pensamento de Rodolfo Kusch e Enrique Dussel alcançou projeção internacional e, especialmente o último, fez contribuições relevantes ao debate sobre o colonialiso. Ambos, a pesar de não terem consagrado expressamente o Terceiro Mundo, não ficaram imunes à sua influencia, incorporando-o em seus tratados. Como exemplo, Kusch, frente à "saturação ontológica do Ocidente", declarou: "A solução nasce [...] a partir da própria cultura na diluição do ser em medo, da cohabitação com o absoluto, assumindo todo o estar-sendo. Porém, a partir do estar-siendo se deduz também [...] que o acesso ao absoluto se locomoveu ao Terceiro Mundo, onde ficou a possibilidade de uma salvação que solucionasse, ou ao contrario, uma solução que salve" (Esbozo de una antropología filosófica americana, Buenos Aires, Castañeda, 1978, p. 99). No entanto, Dussel, recordando Bartolomé de Las Casas, sustenta que ele "supôs descubrir em pleno século XVI, o pecado que existe há cinco séculos na história universal: o pecado da dominação imperial europeia sobre suas colônias do Terceiro Mundo (América Latina, mundo árabe, África negra, India, sudeste asiático, China). O pegado originário da modernidade foi ter ignorado o índio, o africano, o asiático, o "outro" sagrado, tendo-os coisificado como um instrumento dentro do mundo da dominação norte-atlântica" (América latina: dependencia y liberación, Buenos Aires, Fernando García Cambeiro, 1973, p. 194).

${ }^{45}$ Eduardo Astesano, Nacionalismo histórico o materialismo, Buenos Aires, Pleamar, 1972, p. 206.
} 
de uma etapa; são esses povos que obrigaram a sociedade industrial a se "planetizar", sem confiar na necessidade científica; quem proclamou que a proclamada universalização da etapa capitalista é o resultado de uma planificação política implementada e mantida por meio da violência; e que, entre centros imperiais e sociedades dependentes, a única relação lógica e verdadeira é a exclusão. ${ }^{46}$

O terceiro-mundismo, ao invocar o povo, mostrou uma constância em relação à sua vocação popular. E nesta direção fluiu com o peronismo, com o qual tinha um vínculo histórico e quase casual. Juan Domingo Perón criou, antes do surgimento do Terceiro Mundo e do Não-Alinhamento, a bandeira da Terceira Posição, política internacional pós-Segunda Guerra Mundial que não considerava o alinhamento com os Estados Unidos e à União Soviética, levantando uma alternativa estratégica, porém, também ideológica (ou, mais precisamente, econômica), que optava por um modelo intermediário em relação ao capitalismo e ao socialismo. Perón, já sem o poder, teve a habilidade de se apresentar como pioneiro do terceiro-mundismo, por mais que a Terceira Posição não tivesse algumas características clássicas dele, como a unidade entre os continentes periféricos:

O Justicialismo, há quase vinte anos, estabeleceu como posição ideológica uma "terceira posição", convencido de que o caminho do imperialismo capitalista conduzia, por uma falha, ao imperialismo soviético. Depois de vinte anos, parece que as terceiras partes do mundo entendem assim, o que deu lugar ao chamado "Terceiro Mundo", cuja posição é a mesma esboçada pelo Justicialismo em $1945 .{ }^{47}$

O grupo da revista Antropología 3er Mundo, também asociado às Cátedras Nacionais e ao socialismo nacional, era explícitamente peronista, e demonstrou a comunhão de objetivos entre o terceiro-mundismo e a terceira posição:

Ao se colocar como "terceira posição" [...] o Justicialismo se converteu em uma doutrina totalmente fidedigna às lutas de afirmação nacional, porque, ao afirmar que existe uma "terceira posição", está afirmando a irredutibilidade de um "Terceiro Mundo"; e com a afirmação desta irredutibilidade, fecham-se todas as portas para o menosprezo por tais lutas, tática tradicional dos imperialismos. ${ }^{48}$

Recapitulando, acreditamos que, nesta fase, o terceiro-mundismo argentino acaba se expandindo no campo cultural, e se constitui em sensibilidade hegemônica, o que foi comprovado por sua presença em disciplinas diversas, como teologia, psicologia, esoterismo, estética etc.; por sua centralidade de revistas; por sua influência nas ciências sociais (o Terceiro Mundo não só é assunto para elas, mas também alterou seu método e teoria); por sua localização no debate político, dialogando com tendências afins de grande relevância na sociedade argentina, como o

${ }^{46}$ Amelia Podetti, “Racionalidad, irracionalidad y Tercer Mundo”, prólogo a Norberto Wilner, Ser social y Tercer Mundo: elementos para una lógica de lo nacional, Buenos Aires, Galerna, 1969, p. 42.

${ }^{47} J u a n$ Domingo Perón, La hora de los pueblos, Buenos Aires, Ediciones de la Liberación, 1973, p. 128

${ }^{48}$ Norberto Wilner, "La tercera posición justicialista y el marxismo", Antropología 3er Mundo, n. 9, Buenos Aires, 1972, p. 29. 
peronismo e o socialismo nacional. A sensibilidade terceiro-mundista, ao mesmo tempo, alcançou sua maturidade no sentido de que já não se reduzà repetição de frases feitas - por exemplo, de simples solidariedade com o resto do Terceiro Mundo-, mas avança com a formulação de conceitos próprios que entram em conflito com outros sistemas de ideias (com o marxismo, por exemplo).

\section{Tercera etapa: crítica e decadência (1975-1987)}

Assim como o anticomunismo cresceu na medida em que o comunismo se fortaleceu, o antiterceiro-mundismo que surgiu na Argentina refletiu o êxito da expansão de um terceiro-mundismo que, como quase toda ideologia, criava também anticorpos.

Mesmo que a expressão da crítica ao terceiro-mundismo tenha acabado em 1975, com Juan José Sebrelli, os ataques contra a doutrina datavam de anos anteriores. A primeira manifestação foi realizada por Mariano Grondona. Analítico e imparcial, após analisar as distintas posturas políticas frente ao Terceiro Mundo, chegou à conclusão de que a América Latina não poderia se infiltrar em uma aliança completamente terceiro-mundista, simplesmente porque sua identidade era outra:

Do ponto de vista do "Terceiro Mundo", a América Latina é um "proletário conformista": submetida, como as nações asiáticas, à "mais valia" internacional, porém, incapaz de levar, como elas, a energia do ressentimento antibranco, anticristão e anticolonial. Não é esta, de fato, uma posição desconcertante? Pobres no campo material e ricos no espiritual, os povos latino-americanos devem desatar de vez o nó deste dilema crucial. E o farão mediante ao pleno acesso ao ocidente, por meio do desenvolvimento, ou, pelo contrário, fundindo-se definitivamente ao proletariado internacional. ${ }^{49}$

Menos elaboradas, ou simplesmente descuidadas, foram as intenções de Manuel Tagle e Carlos Sacheri, cuja hostilidade obedecia a motivos religiosos. Tagle, em conferência pronunciada no simbólico Jockey Club, atacava as invenções sobre as quais se sustentava o Terceiro Mundo: a ficção do subdesenvolvimento, desmentida pela presença da mesma Argentina, mais próxima dos desenvolvidos do que dos pobres; ou a ficção ideológica, já que simulava a precedência do capitalismo e do comunismo, quando na verdade tinha rancor do primeiro e simpatia pelo segundo. É aqui que chega ao centro do seu argumento: a conspiração comunista contra a Igreja, que enganou muitos clérigos "envolvidos por uma aventura política de filiação comunista recoberta pela maliciosa máscara de uma pseudorreligiosidade". ${ }^{50}$ Anos atrás, Sacheri tinha denunciado como o terceiro-mundismo construía uma igreja clandestina internacional, que tinha no Movimento de Sacerdotes para o Terceiro Mundo

\footnotetext{
${ }^{49}$ Mariano Grondona, La Argentina en el tiempo y en el mundo, Buenos Aires, Primera Plana, 1967, p. 217. 50Manuel Tagle, ¿Qué es el Tercer Mundo?, Buenos Aires, Centro de Estudios sobre la Libertad, 1974, p. 11.
} 
seu correlato argentino. Para Sacheri, era claro que o socialismo, o marxismo e o terceiro-mundismo eram a mesma coisa. ${ }^{51}$

$\mathrm{O}$ ataque mais pesado veio, sem dúvida, da esquerda. Juan José Sebrelli, ensaísta de grande carreira, saiu em defesa do marxismo frente aos embates do terceiro-mundismo peronista mencionados. Acusava seus rivais de apresentar o Terceiro Mundo como "um mundo em si, como uma entidade pessoal dotada de razão, perfeitamente limitada e classificável, como uma formação econômico-social determinada e específica"; foi personificado, sendo que, na verdade, "não é uma realidade objetiva, não é uma categoria histórica, não é nada além de uma figura ideológica que entende como ideologia uma sublimação da realidade em proveito de uma determinada práxis política".52

Assim, tirava o crédito do nacionalismo que incentivava os países pobres e que desvirtuava o caminho revolucionário. Para Sebrelli, no terceiro-mundismo o nacional escondia o social ao se basear em uma mentira: a unidade de interesses entre as oligarquias nativas e o proletariado. Se o importante era a cruzada nacional pela libertação, e se esta cruzada se apresentava como uma missão que unia a sociedade em seu conjunto, alterava-se a luta de classes e, finalmente, perpetuava-se a opressão. Por fim, ao exaltar o agrupamento dos povos dependentes, envolvia-se em um falso internacionalismo:

A luta revolucionária é uma só no mundo todo, havendo condições objetivas para a solidariedade dos oprimidos do Primeiro, Segundo e Terceiro Mundo, ainda que estes não tenham consciência desta unidade de interesses. ${ }^{53}$

Assim, enquanto no terceiro-mundismo se abandonava a fé nas classes proletárias dos países ricos, Sebrelli revalidava a solidariedade internacional do marxismo clássico. Se para os primeiros a nova luta de classes era aquela que incentivava os povos periféricos contra os países do centro, para Sebrelli, ainda era pertinente esperar que as coisas se acalmassem.

O imperialismo não substituí a luta de classes pelas nações; ao contrário, ao unificar o mundo pela difusão do sistema capitalista até o último canto do mundo, universaliza a contradição entre capital e trabalho, levando a revolução socialista à escala mundial. As teses essenciais do marxismo não perderam, portanto, sua universalidade..$^{54}$

Como bom polemista, Sebrelli construía sua crítica simplificando o discurso terceiro-mundista que, de forma geral, incluía sinceros ideais revolucionários - e envolvia a prática de não identificar seus oponentes. O dele era um terceiro-mundismo que não negava a justiça da luta dos países colonizados; simpatizava com eles e condenava o imperialismo, claro que com estratégias e fundamentos divergentes.

\footnotetext{
${ }^{51}$ Carlos Sacheri, La iglesia clandestina, Buenos Aires, Ediciones del Cruzamante, 1971.

52Juan José Sebrelli, Tercer Mundo, mito burgués, Buenos Aires, Siglo Veinte, 1975, p. 34

53/dem, Ibidem, p. 32.

${ }^{54}$ Idem, Ibidem.
} 
De todo modo, o terceiro-mundismo argentino começaria a decair logo após o texto de Sebrelli. Em 1976, um golpe de Estado faria desaparecer uma democracia já deteriorada, dificultando a vida política e acadêmica de forma dramática. Nas ciências sociais, observou-se o declínio das análises comprometidas com a causa do Terceiro Mundo e, em seu lugar, surgiram estudos mais técnicos focados na dimensão internacional do mesmo. Proliferam nas revistas acadêmicas voltadas às relações internacionais, à economia e às ciências sociais, em geral, artigos sobre o Terceiro Mundo em relação a processos e sucessos da época, como a luta para instaurar a Nova Ordem Econômica Internacional - impulsionada pelos países não alinhados e pelo Grupo dos 77 - a nova divisão do eixo em Norte/Sul, a cooperação Sul-Sul, ou, regionalmente, a política exterior argentina (discutindo, por exemplo, o rejeição do governo militar ao não-alinhamento). ${ }^{55}$

Esta atividade - que não foi modificada com o retorno da democracia dissolve-se até 1987. A partir daí, as aparições do Terceiro Mundo seriam muito isoladas, seguindo uma tendência global que se fortaleceria com o fim da Guerra Fria.

\section{Conclusões}

Na sua época de ouro, que estabelecemos ser entre 1968 e 1974, o terceiro-mundismo conseguiu se constituir em uma das sensibilidades hegemônicas do campo intelectual argentino, o que se demonstrou pela ampla recepção das disciplinas e ideológica que tiveram seus princípios, assim como por iniciativas editoriais e movimentos culturais que foram criados com base nessa inspiração. Foi também um incentivador para o debate de ideias, que ganhou vida em um período particularmente ativo do pensamento político argentino, entre os anos sessenta e setenta, agregando uma perspectiva internacional.

Tendo sido uma sensibilidade dominante - e não excludente -, pôde incidir na evolução posterior da história das ideias. Talvez os autores que criaram teorias sobre o Terceiro Mundo não tenham sido lidos, portanto, nem citados, porém, este aparente esquecimento no qual caíram não anula a possibilidade de que tenham preparado o terreno para uma reflexão maior sobre os problemas relacionados. Se a opção descolonial ou o pensamento alternativo à globalização se destacaram nos últimos anos na Argentina, isso pode ter se dado devido àquela sensibilidade que se conseguiu instalar na realidade dos povos periféricos como um todo.

\footnotetext{
${ }^{55}$ Alguns exemplos: Aldo Ferrer, "La crisis del sistema trilateral y América Latina”, Estudios Internacionales, n. 42. Santiago, 1978; Cesare Augusto Carazzini, "Primero, Segundo y Tercer Mundo: hacia un nuevo orden económico mundial", Cuadernos de planeamiento, n. 2, Buenos Aires, 1977; Cesare Augusto Carazzini, "Relaciones entre el Primer y el Tercer Mundo: planes para una solución”, Cuadernos de planeamiento, n. 1, Buenos Aires, 1976; Eduardo Rabinovich, El nuevo orden económico internacional: una visión del poder en el sistema internacional, Buenos Aires, El Cid, 1984; Guillermo O’Donnell, "El aparato estatal en los países del tercer mundo y su relación con el cambio socioeconómico", Revista Internacional de Ciencias Sociales, n. 4, París, 1980; Roberto Russell y Mónica Hirst, "Democracia y política exterior: Ios casos de Argentina y Brasil", Estudios Internacionales, n. 80, Santiago, 1987; Roberto Russell y Teresa Carballal, "América Latina: ¿Hacia qué nuevo orden internacional?", Estudios Internacionales, n. 46, Santiago, 1979; Salvador Lozada, "Ubicarnos en el Tercer Mundo y los No Alineados", Realidad Económica, n. 52-53, Buenos Aires, 1983. Anteriormente, mas no mesmo sentido: Carlos Pérez Llana, "América Latina y los países no alineados", Estudios Internacionales, n. 24, Santiago, 1973.
} 